\title{
Supervised injection sites: Prejudice should not trump evidence of benefit
}

\author{
Maria Zlotorzynska PhD, Evan Wood MD PhD, Julio S. Montaner MD, Thomas Kerr PhD
}

$\mathrm{I}$ n 2011, the Supreme Court of Canada issued a unanimous ruling granting Insite, Canada's first government-sanctioned supervised injection facility for people who use illicit drugs, an extended exemption to operate, stating "Insite saves lives. Its benefits have been proven." This decision marked a triumph for evidence-based medicine and public health, and presented opportunities to extend this form of intervention to other jurisdictions in Canada. However, with the recent tabling of Bill C-65, this opportunity may be under threat.

Bill C-65, known as the Respect for Communities Act, introduces new requirements to be fulfilled by supervised injection facilities before they can be granted an exemption from the Controlled Drugs and Substances Act. Without this legal exemption, people who use an injection facility risk criminal prosecution for drug possession. It appears that the federal government would see Canada's drug policy continue to follow a strategy that has proven both costly and ineffective at combatting problematic drug use.

The proposed legislation would give the federal Minister of Health sole authority in deciding whether to approve a facility's application for exemption. Special emphasis is placed on the need for broad community and police support as part of the application process, and the bill empowers the Minister to seek input directly from the general public regarding any proposed supervised injection facility.

Many of Canada's leading health bodies, including the Canadian Medical Association and the Canadian Nurses Association, have expressed concern that this legislation places such onerous burdens on applicants that it is doubtful any new facilities will be approved. Furthermore, the passing of the bill could potentially result in Insite's closure, given that the facility would thus be required to reapply for an exemption in 2014 .

Although community consultation is important in ensuring that public health and public safety interests are balanced, this bill appears to be structured in such a way that the voices of opponents to harm reduction, however illinformed, are privileged above others who speak to the robust evidence showing that supervised injection facilities save lives. The result is that Bill C-65 may prioritize the opinions of people who find intravenous drug users distasteful over the need to use effective measures to limit the spread of disease and save lives. This proposed legislation seems to ignore evidence from a decade of experience in Vancouver and, in so doing, jeopardizes the expansion of these services to other Canadian cities where a need for them has been identified. ${ }^{2}$

Insite opened in Vancouver in 2003 as a response to devastating twin epidemics of $\mathrm{HIV}^{3}$ and drug overdoses. ${ }^{4}$ A large body of peerreviewed research, published in leading medical journals, has documented the various benefits of the program, including reductions in syringe sharing and fatal overdoses, and increased uptake of addiction treatment. ${ }^{5}$ Three separate studies have found Insite to be cost-effective. ${ }^{6-8}$ Meanwhile, the feared negative consequences of opening Insite have failed to materialize. Although concerns persist that supervised injection facilities attract crime and increase drug use, research undertaken in Vancouver has shown that such fears are unfounded. The results of several studies suggest that disorder associated with public injecting has declined. ${ }^{5}$ The rigorous scientific evaluation of Insite, as well as the evidence derived from the 90 other supervised injection facilities internationally, ${ }^{9}$ support increasing these services as part of a comprehensive response to drug use and its associated harms.
Competing interests: None declared.

This article has been peer reviewed.

Correspondence to: Thomas Kerr, uhri-tk@cfenet.ubc.ca

CMAJ 2013. DOI:10.1503 /cmaj.130927 
The opposition to supervised injection in Canada ultimately comes down to a question of values. The central arguments offered by opponents of facilities like Insite may be summarized as follows: such facilities enable drug use and send a message to drug users that society has given up on their ability to stop using drugs; money should be spent on abstinence-based treatments, not programs that accommodate active drug use; and drug use constitutes a moral failing that is best dealt with through punishment and control.

These arguments are easily countered with evidence. A large body of scientific research shows that addiction is a chronic relapsing condition and that many people cycle in and out of active use. ${ }^{10}$ Thus, although there is a role for abstinence-based programs, harm-reduction models serve to decrease risk during phases of active use. Moreover, attempts to control addiction through criminal justice measures have proven neither effective nor economical. The criminalization of drug users has also been shown to increase high-risk behaviours and elevate the risk of acquiring infectious disease. ${ }^{11}$

Supervised injection facilities and other harm-reduction initiatives are not antithetical to abstinence-based programs and their associated values. Insite operates within the same building as a detox centre and transitional housing for people seeking to cease drug use altogether. Indeed, research has found that supervised injection services can play a role in facilitating uptake of addiction treatment services and promoting cessation from drug use. ${ }^{12}$ Other studies have shown injection facilities have no adverse effects on drug use in the broader community, such as increasing rates of initiation into injecting among vulnerable populations. ${ }^{13}$ Ultimately, these facilities appear to help advance the very goals that their opponents espouse.

We must focus on how to facilitate the implementation of new supervised injection facilities in Canada, not on whether such facilities should be opened. The passage of Bill C-65 into law could further entrench an agenda set by the National Anti-Drug Strategy that appears to ignore harm reduction in the face of overwhelming scientific evidence of its benefits. The bill was not debated by Parliament before the summer recess. We believe it should not be reintroduced when the House of Commons reconvenes, unless it is dramatically altered to promote evi- dence-based drug policy that emphasizes the health and human rights of drug users. Local health officials should be empowered to make evidence-based decisions about what interventions are offered to people who inject drugs. These decisions should only consider concerns about public safety for which there is robust evidence. Concerns that arise out of prejudice and ignorance, for which there are no sound arguments, should be set aside. It is rare that a government is given the opportunity to build policy that is simultaneously fiscally sound, compassionate and backed by high-quality scientific research. We should not allow the opportunity to do the right thing to pass by again.

\section{References}

1. Canada (Attorney General) v. PHS Community Services Society, 2011 SCC 44, [2011] 3 S.C.R. 134

2. Bayoumi AM, Strike C, Jairam J, et al. Report of the Toronto and Ottawa Supervised Consumption Assessment study. Toronto (ON): St. Michael's Hospital and the Dalla Lana School of Public Health, University of Toronto; 2012.

3. Patrick DM, Strathdee SA, Archibald CP, et al. Determinants of HIV seroconversion in injection drug users during a period of rising prevalence in Vancouver. Int J STD AIDS 1997;8:437-45.

4. Tyndall M, Johnston C, Craib K, et al. HIV incidence and mortality among injection drug users in Vancouver - 1996-2000 [abstract]. Can J Infect Dis Med Microbiol 2001;12:69B.

5. Wood E, Tyndall MW, Montaner JS, et al. Summary of findings from the evaluation of a pilot medically supervised safer injecting facility. CMAJ 2006; 175:1399-404.

6. Bayoumi AM, Zaric G. The cost-effectiveness of Vancouver's supervised injection facility. CMAJ 2008;179:1143-51.

7. Vancouver's Insite service and other supervised injection sites: What has been learned from research? Final report of the Expert Advisory Committee. Ottawa (ON): Expert Advisory Committee of Supervised Injection Site Research; 2008.

8. Andresen MA, Boyd N. A cost-benefit and cost-effectiveness analysis of Vancouver's supervised injection facility. Int $J$ drug Policy 2010;21:70-6.

9. Bravo MJ, Royuela L, De la Fuente L, et al. Use of supervised injection facilities and injection risk behaviours among young drug injectors. Addiction 2009; 104:614-9.

10. Camí J, Farre M. Drug addiction. N Engl J Med 2003;349:975-86.

11. Small W, Kerr T, Charette J, et al. Impacts of intensified police activity on injection drug users: evidence from an ethnographic investigation. Int J Drug Policy 2006;17:85-95.

12. Wood E, Tyndall MW, Zhang R, et al. Attendance at supervised injecting facilities and use of detoxification services. $N$ Engl J Med 2006;354:2512-4.

13. Kerr T, Tyndall M, Zhang R, et al. Circumstances of first injection among illicit drug users accessing a medically supervised safer injection facility. Am J Public Health 2007;27:1228-30.

Affiliations: British Columbia Centre for Excellence in HIV/AIDS (Zlotorzynska, Wood, Montaner, Kerr), St. Paul's Hospital; Department of Medicine (Wood, Montaner, Kerr), University of British Columbia, St. Paul's Hospital, Vancouver, $\mathrm{BC}$

Contributors: Maria Zlotorzynska and Thomas Kerr developed the original arguments, and presented and completed the first draft of the manuscript. Evan Wood and Julio Montaner provided extensive comments on the draft and contributed to the revision of the manuscript. All of the authors approved the final version submitted for publication. 